\title{
ON THE RATIO OF TWO SETS IN REAL LINE
}

\author{
D. K. Ganguly And Dhananjoy Halder
}

Abstract. In this paper, assuming Martin's axiom we show that there exists a Lebesgue measurable subset $A$ of the real line $\mathbb{R}$ such that the set $\{c \in \mathbb{R}: R(A, c+A)$ contains an interval $\}$ is non-measurable. Here the set $R(A, c+A)=\left\{\frac{a}{c+a^{\prime}}: a, a^{\prime} \in A, c+a^{\prime} \neq 0\right\}$. Also other two results on the ratio set of linear sets are presented.

Mathematics subject classification (2010): Primary 28A05, Secondary $26 A 15$.

Keywords and phrases: Bernstein set; Borel set; Difference set; Property of Baire; Ratio set.

\section{REFERENCES}

[1] M. Baicerzak, J. Hejduk, And J. E. Baumgartner, On certain $\sigma$-ideals of sets of sets, Real Anal. Exch., 14/2, 447-453.

[2] N. C. Bose Majumder, On some properties of sets with positive measure, Annali Dell' Univ. di Ferrara (N. S.) Sez VII- Sci. Mat., X, 1 (1962), 1-12.

[3] J. Ceder And D. K. Ganguly, On projection of big planar sets, Real Anal. Exch., 9 (1983-84), 206-214.

[4] Miljenko Crnjac, Boris Guljaš and Harry I. Miller, On some questions of Ger, Grubb and Kraljević, Acta Math. Hung., 57, 3-4 (1991), 253-257.

[5] P. Erdos And J. C. Oxтовy, Partitions of the plane into sets having positive measure in every non-null measurable product set, Trans. Amer. Math. Soc., 79, (1955), 99-102.

[6] D. K. Ganguly and S. Basu, On ratio sets of real number, Indian J. Pure Appl. Math., 23, 1 (1993), 15-20.

[7] Z. KomineK, Some generalizations of the theorem of S. Piccard, Prace Nauk. Univ. Slqski Katowice, Prace Mat., 4, (1973), 31-33.

[8] M. E. KuCZMA AND M. KuCZMA, An elementary proof and an extension of a theorem of Steinhaus, Glasnik Mat. Ser. III, 26), 6, (1971) 11-18.

[9] D. A. Martin And R. M. Solovay, Internal Cohen extension, Ann. Math. Logic, 2, (1970), $143-$ 178.

[10] H. I. Miller, Generalization of a classical theorem of measure theory, Radovi Akademije Nauka i Umjetnosti BiH, XLV (1973), 45-48.

[11] H. I. MILLER, Relationships between various gauges of the size of sets of real numbers, Glasnik Mat. Ser. III, 29, 9 (1974), 59-64.

[12] J. C. Охтовy, Measure and Category, Second Edition, Springer-Verlag, NY, Heidelberg Berlin (1980).

[13] S. PICCARD, Sur les ensembles de distances des points d'un espace Euclidean, Neuchatel (1933).

[14] H. Steinhaus, Sur les distance des points des ensembles de measure positive, Fund. Math., I (1920), 93-104. 